\title{
TINJAUAN TEORI KEPERAWATAN KESEHATAN KERJA
}

\author{
Henny Permatasari ${ }^{1 *}$
}

1. Keperawatan Komunitas Fakultas Ilmu Keperawatan Universitas Indonesia, Depok 16424, Indonesia

*Email: henny@ui.ac.id

\begin{abstract}
Abstrak
Populasi pekerja adalah salah satu kelompok dalam masyarakat yang sangat rentan mengalami penurunan derajat kesehatan akibat sakit atau mengalami kecelakaan kerja. Tempat kerja memiliki faktor heatlth hazards yang berdampak terhadap tingginya angka kesakitan dan kematian bagi pekerja. Upaya meningkatkan derajat kesehatan dan perlindungan terhadap pekerja dilakukan oleh perawat kesehatan kerja melalui upaya pencegahan primer, sekunder dan tersier yang dilakukan dengan menggunakan strategi intervensi keperawatan komunitas dengan berbagai pendekatan. Tulisan ini bertujuan memberikan pemahaman terhadap konsep Keperawatan Komunitas pada Agregate Pekerja, meliputi antara lain; Pengertian dan Tujuan Keperawatan Kesehatan Kerja, Pekerja Sebagai Aggregates, Peran dan Fungsi Perawat Kesehatan Kerja, Faktor-faktor yang Mempengaruhi Kesehatan Pekerja, Strategi Intervensi Keperawatan Kesehatan Kerja, Level dan Bentuk Intervensi Keperawatan Kesehatan Kerja, serta, Teori dan Model yang dapat diaplikasikan dalam Pelayanan Keperawatan Kesehatan Kerja.
\end{abstract}

Kata kunci: health hazards, model keperawatan kesehatan kerja, pekerja, perawat kesehatan kerja, tempat kerja

\section{Abstract}

Workers was a population aggregate who were being exposed to work related health hazards. Maintaining the health of the workers was an important role of occupational health nursing. The nurse work cooperatively with the worker, the worker's family, the workplaces and the community as well. The practice of occupational health nursing is focused on the promotion of health in the workplaces by used variety strategies of primary, secondary and tertiary level of preventions. The purpose of this scientific paper work were to give a deep understanding in conceptual, theoretical on Occcupational Health Nursing and the worker aggregates as well. This paper also contain the whole topics such as: worker as population aggregate, nursing role in occupational health, types of occupational hazards and associated health effects, level of prevention, use the Occupational Health Nursing Model to explain work- health interactions.

Key words: health hazards, occupational health nursing model, worker, occupational health nursing, workplace

\section{Pendahuluan}

Jumlah tenaga kerja di seluruh penjuru dunia meningkat secara global. Menurut Organisasi Perburuhan Dunia/ International Labour Organisation (ILO) saat ini terdapat sekitar 2,6 milyar angkatan kerja (ILO, 2005).

Peningkatan jumlah tenaga kerja terjadi sebagai akibat meningkatnya jumlah penduduk di dunia dan kebutuhan pekerjaan yang layak bagi masyarakat. Indonesia sebagai salah satu negara yang sedang berkembang juga mengalami peningkatan jumlah tenaga kerja yang signifikan. Berdasarkan data dari Biro Pusat Statistik (BPS) pada tahun 2005, terdapat 101,5 juta pekerja, dengan jumlah perusahaan atau institusi kerja berjumlah 120.000 .
Pekerja merupakan salah satu kelompok dalam masyarakat yang berisiko mengalami berbagaimasalah kesehatan. Menurut ILO (2005), terdapat lebih dari 2 juta kasus kematian tiap tahunnya karena kecelakaan dan penyakit akibat kerja (PAK) yang fatal. Di Indonesia, angka kesakitan pekerja pada tahun 2005 adalah 92.783. Angka kecelakaan pekerja pada tahun yang sama adalah 8904. Sedangkan angka kematian pekerja adalah 1699 (Jamsostek, 2005).

Upaya untuk meningkatkan derajat kesehatan dan keselamatan, pekerja mendapatkan perhatian dari seluruh dunia dengan diprioritaskannya occupational health/ kesehatan kerja dalam kebijakan Healthy People 2000. Kebijakan yang bersifat global ini ditujukan untuk memperbaiki status kesehatan pekerja, 
mengurangi faktor risiko di tempat kerja, memperbaiki dan meningkatkan pelayanan kesehatan kerja, serta mengurangi terjadinya kecelakaan dan penyakit akibat kerja (Eigsti, Guire, \& Stone, 2002).

\section{Keperawatan Komunitas pada Agregate Pekerja}

\section{Pengertian dan Tujuan Keperawatan Kesehatan Kerja}

Keperawatan kesehatan kerja/ occupational health nursing (OHN) adalah cabang khusus dari keperawatan komunitas yang merupakan aplikasi dari konsep dan frame work dari berbagai disiplin ilmu (keperawatan, kedokteran, kesehatan masyarakat, ilmu sosial dan perilaku, prinsip-prinsip manajemen) yang bertujuan meningkatkan dan memelihara status kesehatan pekerja serta melindungi pekerja dari kecelakaan kerja dan faktor risiko bahaya di tempat kerja (health hazards) dalam konteks lingkungan kerja yang sehat dan aman (American Asscociation of Occupational Health Nursing/ AAOHN dalam Nies \& Swansons, 2002; Stanhope \& Lancaster, 2004).

\section{Pekerja Sebagai Aggregates}

Bekerja atau menjadi seorang pekerja adalah salah satu tugas perkembangan manusia dewasa (Duval \& Miller, 2000, dalam Friedman, 2003). Bekerja adalah tuntutan peran sosial dalam kehidupan manusia yang harus dilaksanakan oleh semua orang, sehingga ketika memasuki usia dewasa, semua individu melaksanakan peran sebagai pekerja (Rogers, 1994, dalam Stanhope \& Lancaster, 2004). Rogers juga menyebutkan bahwa aktifitas kerja adalah sumber produktifitas dan sarana mengembangkan serta mengekspresikan diri. Arti pekerjaan menjadi sangat penting tidak hanya bagi individu tetapi mempengaruhi integritas sosial dan ekonomi keluarga pekerja.

Populasi pekerja adalah salah satu kelompok rentan mengalami penurunan derajat kesehatan akibat sakit atau mengalami kecelakaan kerja. Tempat kerja memiliki heatlth hazards yang berdampak terhadap tingginya angka kesakitan dan kematian pekerja (Oakley, 2002). Satu studi yang dilakukan oleh
National Institute of Safety and Health/ NIOSH (2006) menunjukkan, 137 pekerja meninggal setiap hari diAmerika sebagai pengaruh penyakit akibat kerja yang bersumber dari health hazards. Di Indonesia, angka kesakitan pekerja pada tahun 2005 adalah 92.783, angka kecelakaan pekerja adalah 8904, sedangkan angka kematian pekerja adalah 1699 (Jamsostek, 2005).

\section{Peran dan Fungsi Perawat Kesehatan Kerja}

Pada beberapa dekade sebelumnya peran dan fungsi OHN hanya terfokus pada penanganan kasus kegawatdaruratan dan penyakit akut yang dialami pekerja di tempat kerja maka, saat ini peran dan fungsi OHN menjadi lebih luas dan kompleks (Nies \& Swansons, 2002). Lusk (1990, dalam Stanhope \& Lancaster, 2004) mengidentifikasi 8 peran OHN. Kedelapan peran tersebut adalah: (1) Pemberi pelayanan kesehatan; (2) Penemu kasus; (3) Pendidik kesehatan; (4) Perawat pendidik; (5) Pemberi layanan konseling; (6) Manajemen kasus; (7) Konsultan, serta (8) Peneliti.

Berdasarkan peran tersebut, maka fungsi OHN adalah: (1) Melakukan supervisi terhadap kesehatan pekerja; (2) Melakukan surveilens terhadap lingkungan kerja; (3) Mencegah terjadinya kecelakaan kerja; (4) Mencegah terjadinya penyakit akibat kerja; (5) Penatalaksanaan penyakit baik yang berhubungan maupun yang tidak berhubungan dengan pekerjaan, kecelakaan di tempat kerja, serta pelayanan kesehatan dasar; (6) Mengatur dan mengkoordinasikan upaya pertolongan pertama di tempat kerja; (7) Melakukan promosi kesehatan dan pencegahan penyakit di tempat kerja; (8) Melakukan konseling untuk pekerja; (9) Melakukan upaya rehabilitasi untuk pekerja yang kembali bekerja setelah mengalami kecelakaan atau dirawat di rumah sakit; (10) Melakukan pencatatan dan pelaporan kesehatan kerja; (11) Melakukan penatalaksanaan terhadap manajemen pelayanan kesehatan kerja termasuk menetapkan perencanaan, pengembangan kebijakan, pendanaan, staffing dan; (12) melakukan tugas admininstrasi di unit kesehatan atau klinik kesehatan yang tersedia serta; (13) melakukan riset keperawatan kesehatan kerja (AAOHN, 1994, dalam Nies \& Swanson, 2002, 
Dorward, 1993, dalam Oakley, 2004, Eigsti, Guire \& Stone, 2002, Stanhope \& Lancaster, 2004, World Health Organisation, 1982, dalam Oakley, 2002).

\section{Faktor-faktor yang Mempengaruhi Kesehatan Pekerja}

Berdasarkan aplikasi model Epidemiologi, hubungan antara pekerja dan status kesehatan dilihat berdasarkan tiga faktor yang saling mempengaruhi, yaitu pekerja (host), lingkungan (environment) dan health hazards (Stanhope \& Lancaster, 2004). Ketiga faktor yang saling berpengaruh tersebut dapat dijelaskan sebagai berikut:

\section{Pekerja (Host)}

Pekerja merupakan host pada populasi pekerja. Host memiliki karakteristik yang berhubungan dengan meningkatnya risiko untuk terpapar health hazards di tempat kerja. Karakteristik tersebut meliputi: (1) usia; (2) Jenis kelamin; (3) Memiliki atau tidak memiliki penyakit kronis; (3) Aktifitas di tempat kerja; (4) Status imunologi; (5) Etnik; (6) Gaya hidup (Stanhope \& Lancaster, 2004).

Sebagai contoh pekerja yang memiliki risiko tinggi mengalami kecelakaan di tempat kerja adalah laki-laki yang berusia antara 18-30 tahun, memiliki pengalaman kerja kurang dari 6 bulan. Karakteristik host seperti usia, jenis kelamin, dan pengalaman kerja, meningkatkan risiko untuk mengalami kecelakaan kerja akibat kurangnya pengetahuan dan kemampuan mengatasi risiko health hazards serta ketrampilan kerja yang masih rendah. Agregat pekerja ini juga berisiko mengalami penyakit kronis akibat gaya hidup yang kurang sehat seperti perokok, minum alkohol, kurang berolahraga (Stanhope \& Lancaster, 2004; Hitchcock, Schubert, \& Thomas, 2004; Oakley, 2002).

\section{Faktor Risiko Bahaya di Tempat Kerja (Health Hazards)}

Health hazards berupa faktor kimia, fisika, biologi, enviromechanical dan psikologi, terdapat pada hampir semua bentuk institusi kerja (Stanhope \& Lancaster, 2004). Tanpa memandang jenis institusi kerja bersifat tradisional atau modern yang menggunakan teknologi tinggi. Perusahaan yang mengelola jasa (bank, institusi pelayanan kesehatan, hotel dan restoran) juga tidak luput dari bahaya health hazards bagi pekerja (Depnakertrans RI, 2005).

AAOHN (1995 dalam Nies \& Swanson, 2002) menyatakan health hazards kimia berupa debu, asbestos, merkuri, dan zat kimia berbahaya lainnya masuk ke tubuh manusia melalui saluran pernafasan, saluran pencernaan, absorpsi kulit, dan absorpsi sistem penglihatan. Pengaruh terhadap kesehatan manusia adalah gejala sakit kepala, gangguan sistem syaraf pusat, ataksia, luka bakar, gangguan sistem reproduksi serta, penyakit keganasan. Health hazards fisika berupa kebisingan, radiasi, getaran, suhu panas dan dingin, serta gelombang elektromagnetik. Health hazards fisika menimbulkan kerusakan pada sistem pendengaran, gangguan sistem reproduksi, penyakit keganasan, dehidrasi, serta serangan panas.

Health hazards biologi berupa bakteri patogen, jamur, dan virus masuk ke tubuh manusia melalui sistem pernafasan, kontak langsung dengan kulit, sistem pencernaan, ,penglihatan. Dampak terhadap kesehatan adalah mengalami penyakit infeksi virus, bakteri, jamur, seperti penyakit hepatitis B, kulit, infeksi yang menyerang sistem organ manusia.

Sedangkan health hazards enviromechanical adalah segala sesuatu yang berpotensi menimbulkan penyakit atau kecelakaan di tempat kerja. Faktor risiko bahaya ini berhubungan dengan proses kerja atau kondisi lingkungan kerja yang berpengaruh terhadap kesehatan ketika aktifitas kerja tertentu dilaksanakan secara berulang-ulang (Stanhope \& Lancaster, 2004).

Kategori health hazards enviromechanical berisiko menimbulkan masalah gangguan tulang dan persendian, cidera punggung, serta gangguan tidur. Selain itu faktor psikologi di tempat kerja seperti stress kerja dan hubungan yang kurang harmonis dengan atasan dan sesama pekerja dapat menimbulkan health hazards psikososial. Kategori ini dapat menimbulkan masalah psikososial kecemasan, konflik di tempat kerja, stress kerja serta penyakit psikosomatik yang menganggu produktifitas kerja. 


\section{Lingkungan}

Faktor lingkungan adalah faktor-faktor yang mempengaruhi interaksi antara host dan agent dan dapat menjadi mediasi antara host dan agent. Lingkungan digolongkan menjadi fisik dan psikologis. Lingkungan fisik berupa panas, bau, ventilasi yang mempengaruhi interaksi host dan agent. (Stanhope \& Lancaster, 2004). Lingkungan fisik yang kurang nyaman menimbulkan ketegangan bagi pekerja serta memperberat risiko interaksi negatif antara host dan agent. Misalnya pekerja yang terpapar health hazards kimia berada di lingkungan kerja panas dan kurang ventilasi maka akan memperberat risiko timbulnya masalah kesehatan pekerja tersebut. Adapun lingkungan psikologis berhubungan dengan karakteristik tempat kerja meliputi hubungan interpersonal dan karakteristik pekerjaan, berupa rendahnya otonomi, tingkat kepuasan kerja, serta pengawasan yang berlebihan (Eigsti, Guire \& Stone, 2004; Oakley, 2002).

\section{Penatalaksanaan Keperawatan Kesehatan Kerja di Masyarakat}

\section{Strategi Intervensi Keperawatan Kesehatan Kerja}

\section{Pendidikan Kesehatan}

Menurut Anderson dan McFarlane (2000), OHN bertanggung jawab terhadap program pendidikan kesehatan di tempat kerja. Pendidikan kesehatan dirancang sejak awal untuk memberikan promosi kesehatan tidak hanya difokuskan pada pekerja tetapi juga diberikan kepada keluarga pekerja. Keluarga memberikan kontribusi besar terhadap status kesehatan pekerja (Oakley, 2002).

Anderson dan McFarlane (2000) menjelaskan, aktifitas pendidikan kesehatan di tempat kerja dimulai dari pengkajian kebutuhan pekerja dan pihak manajemen terhadap upaya pendidikan kesehatan. Langkah berikutnya menciptakan program pendidikan kesehatan yang efisien, efektifuntuk diimplementasikan di tempat kerja.

Pendidikan kesehatan yang diberikan kepada pekerja difokuskan meningkatkan pengetahuan dan kemampuan pekerja mengenali health hazards di tempat kerja serta upaya mengurangi dampak health hazards terhadap status kesehatan mereka (Eigsti, Guire \& Stone, 2004; Oakley, 2004; Stanhope \& Lancaster, 2004). Pekerja biasanya tidak menyadari ancaman health hazards yang tidak bisa dilihat dengan mata secara langsung (misalnya gas dan asbestos), sehingga mereka menjadi kurang waspada terhadap health hazards tersebut (Eigsti, Guire \& Stone, 2002).

Salah satu tantangan yang dihadapi perawat kesehatan kerja untuk memberikan pendidikan kesehatan yang efektif di tempat kerja adalah minimnya waktu luang yang dimiliki pekerja untuk mengikuti pendidikan kesehatan. Waktu luang yang dimiliki pekerja hanya pada saat istirahat makan siang atau istirahat minum kopi, sehingga dibutuhkan strategi khusus untuk mensiasati permasalahan tersebut (Oakley, 2004).

Strategi yang dapat dilakukan adalah membagikan materi pendidikan kesehatan berupa leaflet, brosur berisi pesan kesehatan saat makan siang di ruang makan. Metode lain yang efektif dan efisien untuk memberikan pendidikan kesehatan di tempat kerja adalah dengan penempelan poster, pemutaran video berdurasi singkat (15- 20 menit) (Eigsti, Guire \& Stone, 2002; Hitchcock, Schubert, \& Thomas, 2004; Ervin, 2002).

\section{Proses Kelompok}

Proses pembentukan kelompok adalah gabungan dari individu atau organisasi yang saling bekerja sama untuk mencapai tujuan khusus tertentu atau kerjasama yang saling menguntungkan (American Association of University Woman/ AAUW, 1981, dalam Helvie, 1998). Kelompok pekerja yang berada di satu institusi kerja adalah kelompok yang dapat diberdayakan untuk mengatasi masalah kesehatan yang ada melalui berbagai intervensi keperawatan yang sesuai untuk kelompok.

\section{Kemitraan/ Partnership}

Partnership adalah hubungan yang terjalin antara profesi kesehatan dan partnernya yaitu individu, keluarga, dan masyarakat yang memiliki kekuatan atau power, hubungan ini bersifat fleksibel, 
mengutamakan negosiasi, saling menguntungkan dalam rangkaian proses berubah dan meningkatkan kapasitas dan kemampuan individu, keluarga dan masyarakat untuk mencapai dan atau memperbaiki kesehatan masyarakat (Schuster \& Goeppinger, 1995, dalam Helvie, 1998).

Berbagai pihak seperti pekerja, perwakilan manajemen perusahaan serta perawat kesehatan kerja dapat membentuk kemitraan atau partnership untuk melakukan upaya promosi kesehatan yang bertujuan meningkatkan, memelihara kesehatan pekerja, meningkatkan produktifits kerja serta memberikan keuntungan perusahaan (Eigsti, Guire \& Stone, 2002; Hitchcock, Schubert, Thomas, 2004; Ervin, 2002).

\section{Pemberdayaan Masyarakat / Commnunity Empowerment}

Menurut Wallerstein (1992, dalam Helvie, 1998), pemberdayaan masyarakat adalah proses aksi sosial meningkatkan partisipasi individu, organisasi dan masyarakat mencapaitujuan peningkatan kemampuan individu dan masyarakat dalam rangka memperbaiki kualitas kehidupan dan peran sosial mereka dalam masyarakat.

\section{Level dan Bentuk Intervensi Keperawatan Kesehatan Kerja}

Semua bentuk intervensi keperawatan komunitas berdasarkan pada konsep pencegahan, demikian juga bentuk intervensi keperawatan kesehatan kerja (Travers \& Doughall, 2000, dalam Nies \& Swansons, 2002). Promosi kesehatan, proteksi, pemeliharaan dan rehabilitasi kesehatan pekerja adalah tujuan yang harus dicapai oleh perawat kesehatan kerja (AAOHN, 1995 dalam Nies \& Swanson, 2002). Saat melaksanakan praktek keperawatan kesehatan kerja, perawat kesehatan kerja menggunakan tiga level strategi pencegahan (Stanhope \& Lancaster, 2004).

Penggunaan tiga level pencegahan ini dimaksudkan menjamin perawat lebih berfungsi melakukan pencegahan timbulnya penyakit, serta aktifmelakukan promosi kesehatan terhadap pekerja. Level pencegahan tersebut dikategorikan menjadi tiga bentuk, yaitu; (1) Pencegahan primer; (2) Pencegahan Sekunder; (3) Pencegahan Tersier. Lebih jelasnya akan diuraikan sebagai berikut:

\section{Pencegahan Primer (primary prevention)}

Pada level pencegahan primer, perawat kesehatan kerja melakukan health promotion dan pencegahan penyakit (Nies \& Swansons, 2004). Menurut Patterson (1994, dalam Nies \& Swansons, 2004), health promotion adalah proses meningkatkan kesadaran, mempengaruhi sikap, perilaku individu mencapai derajat kesehatan yang optimal baik dari segi fisik, mental dan sosial. Pencegahan timbulnya penyakit di tempat kerja diawali dengan meningkatkan pengetahuan pekerja mengenali risiko penyakit akibat health hazards. Saat melaksanakan praktek keperawatan kesehatan kerja, perawat menggunakan tiga level strategi pencegahan, yaitu primer, sekunder dan tersier (Stanhope \& Lancaster, 2004).

Melalui area pencegahan primer, bentuk intervensi yang dilakukan perawat adalah melakukan promosi kesehatan dan pencegahan penyakit. Perawat kesehatan kerja menggunakan berbagai metode pencegahan primer dengan metode "One and One Interaction" sebagai strategi mengevaluasi timbulnya risiko masalah kesehatan dari prilaku pekerja (Roger 2000, dalam Nies \& Ewen, 2001). Strategi ini dilakukan karena perawat kesehatan kerja setiap hari berinteraksi dengan pekerja karena berbagai alasan, misalnya saat melakukan pengkajian, pelayanan terhadap pekerja yang sakit, mengalami kecelakaan, serta melakukan surveillance.

\section{Pencegahan Sekunder (Secondary Prevention)}

Upaya pencegahan sekunder yang dilakukan $\mathrm{OHN}$ diberikan melalui berbagai strategi yaitu pelayanan keperawatan langsung (direct care) untuk kasus penyakit akut dan kecelakaan serta upaya untuk menemukan penyakit sejak awal, dan intervensi lebih dini untuk mengurangi risiko timbulnya kecacatan bagi pekerja.

Bentuk intervensi yang dilakukan oleh perawat kesehatan kerja adalah melakukan skreening kesehatan, pemeriksaan kesehatan secara berkala, 
dengan cara yang relatif mudah dan biaya yang minimal. Skreening kesehatan berupa pemeriksaan kesehatan mata, deteksi dini penyakit kanker, tekanan darah tinggi serta, pemeriksaan gula darah untuk mendeteksi timbulnya penyakit diabetes mellitus. Pencegahan sekunder yang diberikan perawat kesehatan kerja juga berupa penempatan ulang atau evaluasi dan rotasi kerja terhadap pekerja dari satu unit kerja ke unit lain, sehingga pekerja memperoleh situasi yang baru, tidak merasa kejenuhan dengan situasi kerja yang lama (Nies \& Ewen, 2001).

\section{Upaya Pencegahan Tersier (Tertiary Prevention)}

Pada level pencegahan tersier, $\mathrm{OHN}$ berperan dalam upaya rehabilitasi status kesehatan pekerja setelah mengalami sakit yang berat atau masalah kesehatan serius lainnya. Upaya rehabilitasi ditujukan agar pekerja dapat kembali menjalankan tugasnya dengan kemampuan optimal yang dimiliki setelah melewati masa sakitnya.

Bentuk intervensinya mengevaluasi status kesehatan pekerja yang baru saja dirawat di rumah sakit karena menderita penyakit tertentu atau mengalami kecelakaan kerja. Perawat memonitor status kesehatan pekerja (paska di rawat di RS) saat pekerja tersebut kembali bekerja. Termasuk mengidentifikasi kebutuhan khusus pekerja tersebut. Sebagai contoh pekerja yang baru saja dirawat di RS karena myocardial infarction membutuhkan observasi tekanan darah secara teratur serta menghindari aktifitas kerja berat seperti mengangkat beban dan mendorong.

\section{Teori dan Model yang dapat diaplikasikan dalam Pelayanan Keperawatan Kesehatan Kerja}

Pelaksanaan praktek pelayanan keperawatan kesehatan kerja dilakukan dengan mengapilkasikan teori dan model yang berhubungan dengan keperawatan kesehatan kerja. Teori dan model tersebut antara lain adalah: (1) Model Epidemiologi, (2) Model Keperawatan Kesehatan Kerja dari Rogers (1994), (3) Model Promosi Kesehatan untuk Pekerja dari Downie dan Tannahill (1996). Adapun Model Epidemiologi telah dijelaskan pada bagian awal dari tulisan ini. Pada bagian ini penulis hanya akan membahas model "Model Keperawatan Kesehatan Kerja" dari Rogers (1994). Rogers (1994, dalam Stanhope \& Lancaster, 2004), merancang model keperawatan kesehatan kerja dengan memfokuskan kesehatan pekerja yang dipengaruhi oleh lima faktor yang berhubungan langsung dengan kesehatan pekerja. Kelima faktor tersebut adalah:

1. Praktek pelayanan $\mathrm{OHN}$ yang terdiri dari 8 elemen. Kedelapan elemen tersebut merupakan gambaran peran dan tugas $\mathrm{OHN}$, yaitu: menetapkan kebijakan yang berhubungan dengan pelayanan keperawatan kesehatan kerja, menetapkan program perencanaan yang berhubungan dengan manajemen pelayanan keperawatan kesehatan kerja, melakukan pelayanan keperawatan langsung, melakukan surveillans terhadap health hazards di tempat kerja, melakukan kerja sama dengan sumber-sumber yang ada di masyarakat pada saat memberikan pelayanan, memberikan pelayanan keperawatan kesehatan kerja berdasarkan aspek etik dan legal, melakukan riset keperawatan kesehatan kerja;

2. Timkesehatan dan keselamatan kerja yang terdiri dari dokter spesialis kesehatan kerja, dokter umum, ahli kesehatan lingkungan, konsultan gizi, fisioterapist, psikolog, occupational hygienist;

3. Faktor yang ketiga adalah Pekerjaan dan health hazards yang terdapat di lingkungan kerja;

4. Sumber-sumber yang ada di masyarakat, baik yang berupa pelayanan kesehatan rujukan pekerja seperti Rumah Sakit, organisasi pemerintah dan lembaga swadaya masyarakat (LSM) yang memberikan perhatian terhadap populasi pekerja; serta

5. Visi dan misi dari perusahaan atau institusi kerja yang mencakup tujuan, kebijakan dan peraturan yang ditetapkan perusahaan baik yang berhubungan dengan aspek bisnis, ekonomi maupun yang berhubungan dengan kesehatan dan keselamatan kerja termasuk kebijakan perusahaan yang memfasilitasi maupun kurang memfasilitasi peningkatan dan pemeliharaan kesehatan pekerja.

Model Rogers juga menjelaskan praktek pelayanan OHN yang dipengaruhi oleh empat faktor utama yang berhubungan dengan situasi sosial, ekonomi, 
serta perkembangan teknologi dalam masyarakat, yaitu: (1) Keadaan ekonomi; (2) Kecendrungan populasi/ trend populasi; (3) Legislasi politik; serta (4) Faktor ilmu pengetahuan dan teknologi.

\section{Kesimpulan}

Indonesia sebagai salah satu negara yang sedang berkembang memiliki 101,5 juta pekerja, dengan jumlah perusahaan atau institusi kerja berjumlah 120.000 (BPS, 2005). Pekerja merupakan salah satu kelompok dalam masyarakat yang berisiko mengalami berbagai masalah kesehatan. Kebijakan Healthy People 2000, dengan salah satu prioritas meningkatkan derajat kesehatan pekerja memberikan dampak terhadap praktek keperawatan yang diberikan oleh perawat OHN. Perawat kesehatan kerja dituntut untuk memberikan pelayanan keperawatan kesehatan kerja berdasarkan konsep dasar keperawatan kesehatan komunitas di tempat kerja, dengan mengaplikasikan berbagai teori dan model keperawatan kesehatan kerja yang sesuai. Upaya tersebut diharapkan mampu meningkatkan dan memelihara kesehatan pekerja, meningkatkan produktifitas kerja serta memberikan keuntungan bagi institusi kerja (SS, SW, HR).

\section{Referensi}

Anderson, \& McFarlane. (2000). Community as partner: Theory and practice in nursing. Philadelphia: J.B. Lippincott Company, USA.

BPS. (2005). Data statistik ketenagakerjaan. Diperoleh dari http://www.bps.go.id.

Depnakertrans RI. (2005). Pengawasan ketenagakerjaan. Diperoleh dari http://www.depna kertrans.go.id.
Ervin, N.F. (2002). Advanced community health nursing practice: Population focused care. Prentice Hall: New Jersey.

Eugsti, C.S., Guire, L.S., \& Stone C.S. (2002). Comprehensive community health nursing family, aggregate, and community practice. St. Louis: Mosby.

Friedman, M.M. (2003). Family nursing: Research, theory, and practice (5th Ed.). New Jersey: Prentice Hall.

Helvie, O.C. (1998). Advance practice nursing in The community. London: Sage Publications.

Hitchcock, J.E. Schubert, P.E., \& Thomas, S.A. (2004) Community health nursing: Caring in action. Albany: Delmar Publisher

ILO. (2005). Statistic and databases. Diperoleh dari http://www.ilo.org.

Jamsostek. (2005). Angka kematian tenaga kerja Indonesia. Diperoleh dari http://www. jamsostek.go.id.

Nies, M.A., \& Ewen, M.M.(2001). Community health nursing promoting the health of population. Washington: WB Saunders Company.

Nies, M.A., \& Swanson, J. (2002). Community health nursing: Promoting the health of aggregates. Philadelphia: W.B. Saunders Co.

NIOSH. (2006). Data and statistic. Diperoleh dari http//www.cdc/goc/niosh/.

Oakley, K. (2002) Occupational health nursing. Philadelpia: Whurr Publisher.

Stanhope, M., \& Lancaster, J. (2004). Community and public health nursing. St Louis: The Mosby Year Book.

Cinta itu layaknya sebuah energi, tidak dapat dimusnahkan, namun dapat berubah wujud atau bentuk.

-Anonim- 